\title{
Corrosion Behavior of Low Pressure Cold Sprayed AI-PTFE Composites Coating
}

\author{
Guosheng Huang \\ Science and Technology on Marine Corrosion and Protection Laboratory \\ 149-1, Zhuzhou Road, Qingdao, China. \\ huanggs@sunrui.net
}

Keywords: Polymer blends and alloys; PTFE; Low Pressure Cold Spray; Corrosion.

\begin{abstract}
The purpose of this paper is to examine whether low pressure cold spray can deposit high quality Al-PTFE Composites Coating or not. Different Polytetrafluoroethylene (PTFE) content Al-PTFE composite powders were used to deposit composites coating with low pressure cold spraying methods under the parameter about $215^{\circ} \mathrm{C}$ and $0.7 \mathrm{MPa}$ on mild steel substrate. And the microstructure and chemical content are analyzed by SEM and XRD methods. Anticorrosion performance of coating with 2\% PTFE was examined in natural seawater by electrochemical methods. No good quality composites coating can be deposited as the content of PTFE exceeds $5 \%$ because of the low bonding strength of PTFE. The deposition efficiency is much high as the PTFE content increases to $20 \%$. The bond strength between coating and substrate and inner coating are both low due to the high PTFE content in coating and interface. Anticorrosion performance of Al-PTFE is about the same as $\mathrm{Al}$ coating because the content of PTFE in coating is rather small.
\end{abstract}

\section{Introduction}

Cold spray phenomena was discovered occasionally in a wind-tunnel experiment [1]. A particle will adhere to substrate when the particle exceeds a certain velocity [2,3] named critical velocity. It is a bulk solid coating deposition process which is totally different from traditional thermal spray methods. Due to its low processing temperature, cold spray have many advantages over traditional thermal spray, such as low porosity, low oxidation, high density, free of residual stress and no phase transformation, which make cold spray very suitable for part restoration, additive fabrication, rapid prototyping of thermo-sensitive materials and nano-materials.

While equipment of high pressure cold spray is usually very large and unsuitable for on-site operation. To realize on-site operation, development of a portable, low pressure gas dynamic spray (GDS) system is of great interest by researchers [4]. The powder can be fed into divergent section directly without additional powder feeder, which is because of the negative pressure in diverging part of nozzle. This can simplify the cold spray system significantly. Within the nozzle the static pressure is maintained below atmosphere, ensuring that powder is effectively drawn in from the powder feeder. By this way, the gas expands after the nozzle throat, which will lead to a sudden temperature drop. Powder is feeded from the substream of the nozzle, and will not experience high temperature, which will make it suitable for deposit thermal sensitive material. Oxide is always added into powder to activate the surface for deposition in low pressure cold spray, so the temperature is further decreased [5]. Thermal spraying is an effective way to deposit coating of aluminum, copper and stainless steel materials. While by spray methods, PTFE will be decomposed for high temperature over $260^{\circ} \mathrm{C}$. As an emerging technic, cold spray can deposit aluminum coating under the temperature of about $220^{\circ} \mathrm{C}$ [6]. Theoretically, cold spray can be used to deposit Al/PTFE composites coating.

In the present work, a mechanically mixed $\mathrm{Al}, \mathrm{Al} 2 \mathrm{O} 3$ and PTFE powders are prepared to deposit coating on mild steel substrate by low pressure cold spraying. A preliminary study of the coating characteristic and corrosion properties were carried out by electrochemical test methods. 


\section{Experimental Methods}

A commercial Al powder is provided by Shijiazhuang Gaogong Powder company, the purity is 99.9\%. A commercial alumina powder is provided by Zhoucheng Powder company, China, the purity is 99.7\%. A commercial PTFE powder is provided by Aofulong Powder company, China. The powders were observed under ESEM (XL-30 Environmental Scanning Electronic Microscope, manufactured by Philips, Netherland), and the morphology is shown in Fig. 1. Aluminum powder is in quasi-spherical shape with size distribution from $5 \mu \mathrm{m}$ to $45 \mu \mathrm{m}$ which is manufactured by atomized method. The shape of most alumina powder is irregular with size distribution from $20 \mu \mathrm{m}$ to $80 \mu \mathrm{m}$, which is produced by fusion and crashing method. The PTFE powder has a nominal diameter about $5 \mu \mathrm{m}$. Four kinds of raw powders were mechanically mixed on a screen vibrator for 0.5 hour with the following PTFE volume content: $2 \%, 5 \%, 10 \%$ and $20 \%$. The volume ratio between aluminum and alumina is 70:30.

Cold spray coating preparation: Q235 steel was used as substrate with thickness of 3mm, abraded with emery paper of number 280 and 600 in sequence. A commercial low pressure cold spray system was used to deposit coatings (DYMET413, Dycomet Eu. BV, Netherlands). Compressed air was adopted as carrier gas. The gas parameter in the pre-chamber is $0.7 \mathrm{Mpa}$ and $215^{\circ} \mathrm{C}$. The reason for choosing this temperature is that this system only has five temperature steps: $110{ }^{\circ} \mathrm{C}, 215^{\circ} \mathrm{C}$, $325^{\circ} \mathrm{C}, 430^{\circ} \mathrm{C}$ and $550^{\circ} \mathrm{C}$. The transverse speed of spray gun is $5 \sim 8 \mathrm{~cm} / \mathrm{s}$. The distance between nozzle exit and the substrate is about $25 \mathrm{~mm}$.
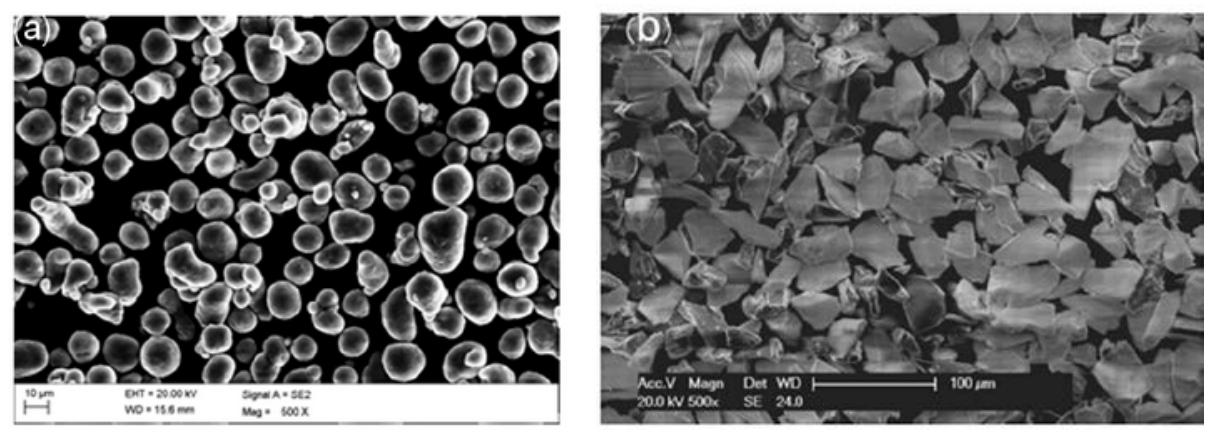

Fig. 1-SEM images of raw $\mathrm{Al}$ and $\mathrm{Al} 2 \mathrm{O} 3$ powders, (a) $\mathrm{Al}$, (b) $\mathrm{Al} 2 \mathrm{O} 3$

As sprayed coating were cut through the cross-section. Microstructural characteristics of corroded surfaces were observed with environmental scanning electron microscope (ESEM). Chemical analyses were carried out with energy-dispersive X-ray spectroscopy (EDX).

Samples preparation for electrochemical test: As sprayed coatings were cut into pieces with size of $20 \mathrm{~mm} * 20 \mathrm{~mm}$, welded with copper lead, sealed with epoxy resin with $10 \mathrm{~mm} * 10 \mathrm{~mm}$ area as working face, distilled with acetone, water and ethyl according to priority after dried with an air drier.

Electrochemical tests were carried out in a conventional three electrodes system with Par 2273 Potentiostat Electrochemistry Workstation (Ametek company, America), SCE as a reference electrode, Pt electrode as a counter electrode, natural seawater (from Maidao corrosion test site of China Corrosion Association) as the electrolyte. The scanning rate for potential dynamic test is $0.4 \mathrm{mV} / \mathrm{s}$. All electrochemical data were collected after the potential become stable (potential variation less than $\pm 3 \mathrm{mV}$ in $5 \mathrm{~min}$ ).

\section{Results and analysis}

\section{Deposition Characteristics}

Two kinds of coatings were obtained under the cold spray operation parameters, and the photograph of cold sprayed different PTFE content $\mathrm{Al}+\mathrm{Al}_{2} \mathrm{O} 3+\mathrm{PTFE}$ coatings are shown in Fig. 2. The 2\% PTFE composites powder can be formed a uniform and good bonding coating on steel substrate. It can also be found that no coating formed while the PTFE content are $5 \%$ and $10 \%$ in raw powders. But when the PTFE content increases to $20 \%$, thickness coating can be formed on the surface of steel. About 3mm thick coating can be formed after each pass. While for powder with $2 \%$ 
PTFE, only about $200 \mu \mathrm{m}$ thick coating can be formed after each pass as shown in Fig.2 (a). The bonding strength of coating (2\%PTFE) is much larger than that of coating (20\% PTFE). Bonding mechanisms are different from each other for these two kinds of coatings, for low PTFE content, aluminum particles impact with substrate and large deformation occurs, bonding locates between aluminum particle and steel substrate, PTFE is embedded into the coatings. While the PTFE content increases, the probability of impaction between aluminum particles and substrate decreases, the PTFE particle prevent the formation of aluminum coating. As the PTFE content continues to increases, the blasting effects of aluminum and alumina to PTFE particles decreases. Under the temperature of about $215^{\circ} \mathrm{C}$, the PTFE particles are softened enough to form PTFE coatings on the steel substrate. But for the low surface energy property of PTFE, the coating quality is very poor as shown in Fig. 2(b). There is no need to discuss the high content PTFE composite coating since it has a poor bonding strength which will lead to no practical application.

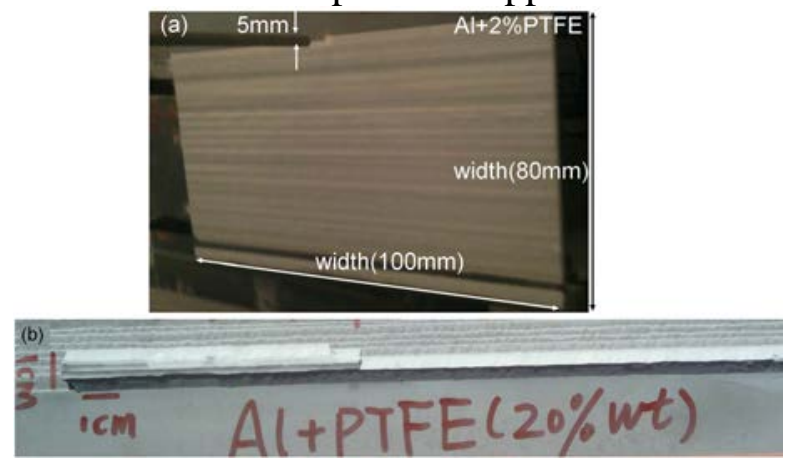

Fig. 2-Photograph of cold sprayed different content Al+Al2O3+PTFE coatings, (a) 2\%, (b) 20\%. SEM and XRD observation

The cross-section morphology of $\mathrm{Al}+\mathrm{Al}_{2} \mathrm{O}_{3}+$ PTFE coating with 2\% PTFE is shown in Fig. 3, it can be seen that the coating thickness is about $450 \mu \mathrm{m}$ after 2 passes. $225 \mu \mathrm{m}$ thickness coating was built up after each spraying pass. The final volume content of each constituent is calculated by EDS as shown in Fig. 3. Final content of PTFE in coating is about $0.6 \%$, much lower than that in raw powder. Alumina content in coating is about $10 \%$, is also lower than $30 \%$ in raw powders.

This phenomenon is determined by the principle of cold spray, the PTFE particle and alumina particle cannot adhere to substrate under the high velocity impaction. There exist only blasting effect as alumina particle impact to substrate by themselves. Alumina can exist in the coating only through embedding way, so most of the alumina particles are rebounded from the substrate. Part of particles of alumina is remained in coating, which will decrease the content comparing to raw powder. Situation for PTFE is different from alumina. PTFE can form coatings on the substrate, but this coating can easily be eroded by alumina and aluminum particles. Only if the content of PTFE is high enough, metal particle cannot erode the PTFE coating off, the PTFE coating then can be remained on the substrate.

The XRD spectrums of raw PTFE powders, aluminum powers, alumina powders and cold sprayed composites coatings are shown in Fig. 4. It can be seen that the alumina powder is a mixture of several kinds of phase including $\alpha, \beta$ and $\theta$. The comparison of raw powders with composite coating indicates that the structure of PTFE doesn't change during the cold spray process. No new substance and phase can be found in the coating comparing to raw powders. In the coating of $2 \%$ PTFE, no peak of PTFE can be found in XRD spectrum. According to the SEM morphology of 2\% PTFE coating, about 0.6\% in volume fraction of PTFE remains in the coating after cold spraying. There exists a possibility that PTFE cannot be detected because of the low content. While according to previous study [7], about $0.1 \%$ content in volume of PTFE in coatings can decrease the friction coefficient to 0.02 0.03. 

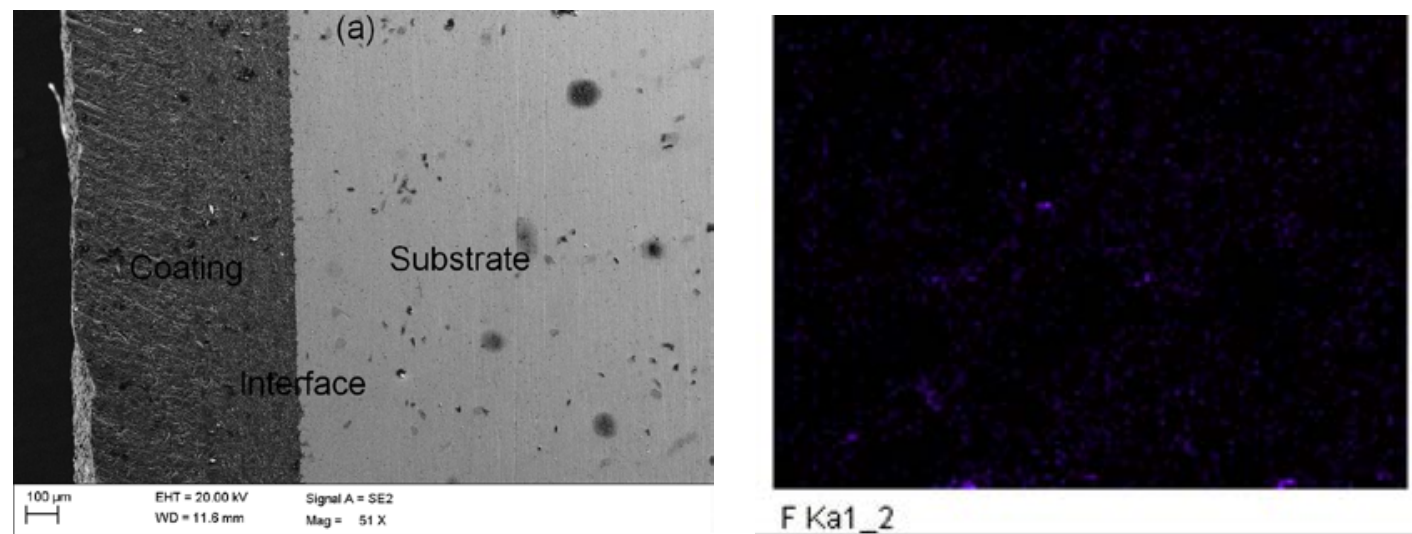

F Ka1_2

Fig. 3-Cross-section SEM morphology of cold sprayed 2\% PTFE composites coatings and its element distribution
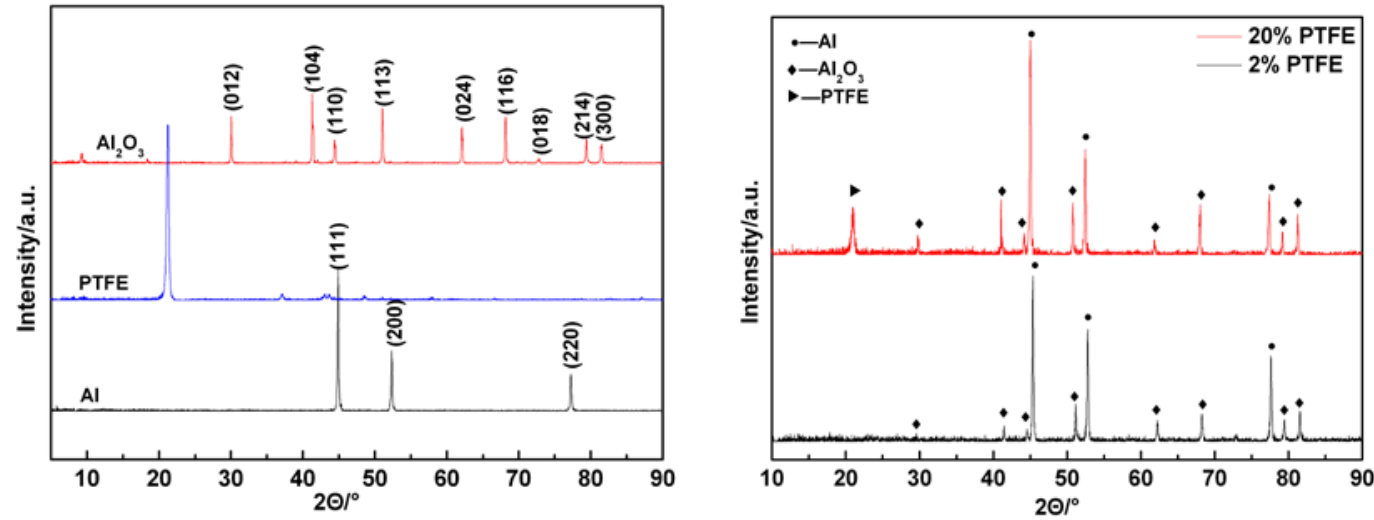

Fig. $4-\mathrm{XRD}$ results of powder and coatings

\section{Corrosion behavior}

Fig. 5 shows the dynamic polarization curves of $\mathrm{Al}+\mathrm{Al}_{2} \mathrm{O}_{3}+$ PTFE with $2 \%$ PTFE content in seawater varying with time. It can be seen from the dynamic polarization curves that the cathodic part has nearly the same slope. These mean that the same cathodic control reaction occurs on the surface, the control reaction is oxygen depolarization which can be written as reaction (1). From anode part, the corrosion behavior of coating can be characterized as anodic active dissolution. It is not easy to prepare samples for electrochemical test for $20 \%$ PTFE coatings because of its poor bonding strength, also it's impossible for this coating to protect the substrate from corrosion and abrasion, so its electrochemical performance won't be discussed here. Corrosion current density can be calculated from Tafel slope, and the fitted results indicate that the current density stabilized at about $0.5 \mathrm{uA} / \mathrm{cm} 2$ after 1 day's immersion.

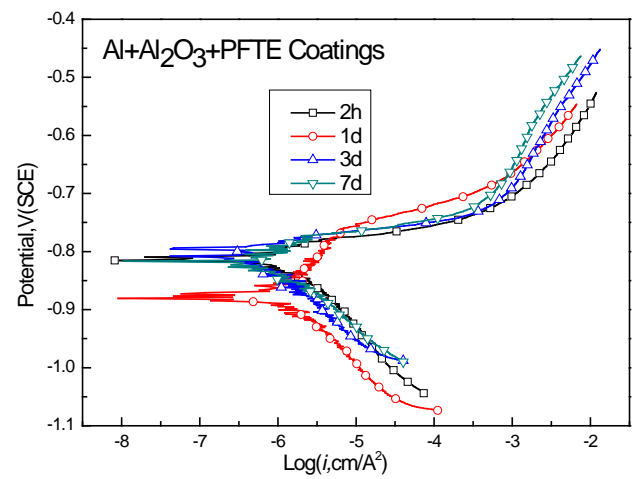

Fig. 5-variation of polarization curves of cold sprayed composites coating in natural seawater

$$
\mathrm{O}_{2}+\mathrm{H}_{2} \mathrm{O}+4 \mathrm{e} \rightarrow 4 \mathrm{OH}^{-}
$$

Literature [8] had investigated the corrosion behavior of cold sprayed aluminum coatings in natural seawater. According to [9], in solution with chloride ions, aluminum will be dissolved directly to $\mathrm{AlOHCl}_{2}$ instead of forming compacting $\mathrm{AlOOH}$ films. At the first few days, the corrosion behavior is forming of compacting $\mathrm{AlOOH}$ film, and passivation behavior can be found in 
polarization curves. After that, active anodic dissolving occurred, then the passivation region disappears from the polarization curves. Literature[10,11] also revealed that corrosion current density of cold spraying coating in seawater is complicated influenced by many parameters such as thickness, powder size distribution, process temperature and so on. And the corrosion current ranges from $0.1 \mathrm{uA} / \mathrm{cm}^{2}$ to $5 \mathrm{uA} / \mathrm{cm}^{2}$. As analyzed above, cold sprayed $\mathrm{Al}+\mathrm{Al}_{2} \mathrm{O}_{3}+\mathrm{PTFE}$ coating has the same corrosion behavior as cold sprayed pure aluminum coatings. This is mainly because of the inertia of PTFE and its low volume content in coatings. Although PTFE has very low surface energy and can compel water molecular from adsorbing to coating surface, low volume content will not improve this performance significantly. On the other hand, no phases change in the coating also means that the corrosion behavior will not change significantly. The only different factor is that the coating mingled about $10 \%$ (volume content) alumina particles, which will reduce the corrosion area of coating surface.

\section{References}

1. Alkhimov A P, Papyrin A N, Kosarev V P, Nesterovich N J, Shuspanov M M(1994) Gas-Dynamic Spray Method for Applying a Coating”, U. S. Patent 5,302,414

2. Francois R, Michel V, Guillaume E(2006) Critical particle velocity under cold spray conditions Surf. \& Coatings Techn. 201: pp.1942-1947

3. Spencer K, Zhang M (2011) Optimisation of stainless steel cold spray coatings using mixed particle size distributions. Surf. \& Coatings Techn. 205: pp.5135-5140

4. Kashirin A, Klyuev O, Buzdygar T, Shkodkin A(2103) DYMET Technology Evolution and Application, International Thermal Spray Conference, Busan, S. Korea, May 13 -16, pp.141-145.

5. Shkodkin A, Kashirin A, Klyuev O, Buzdygar T(2006) The basic principles of DYMET technology, Proceedings of the 2006 International Thermal Spray Conference (Seattle, USA)

6. Zhao Q, Liu Y, Muller S, Liu G(2002) Graded Ni-P-PTFE coatings and their potential applications. Surf. \& Coat.ings Techn. 155: pp. 279-284

7. Liew KW, Chi SY, Kok C K, Low K O(2013) Evaluation on tribological design coatings of Al2O3, Ni-P-PTFE and MoS2 on aluminium alloy 7075 under oil lubrication. Mater. and Design, 48: pp. 77-84

8. Dong C C, Wang H R, Huang G. S, Du M(2010) Corrosion Behavior of Cold-sprayed Aluminum Coating in Seawater, Corr. Sci. and Prot. Techn. 22(2): pp. 90-93

9. Tao Y, Xiong T, Sun C, Kong L, Cui X, Li T, Song G(2010) Microstructure and corrosion performance of a cold sprayed aluminium coating on AZ91D magnesium alloy, Corr. Sci. 52: pp. 3191-3197

10. Grujicic M, Saylor J R, Beasley D E(2003) Computational analysis of the interfacial bonding between feed powder particles and substrate in cold gas dynamic spray process, Appl. Surf. Sci. 319: pp. 211-227

11. Kumar S, Ben M, Ben H, Devan D(2013) Corrosion Protection of 5xxx Series Aluminum-Alloy by Cold Spray Process, International Thermal Spray Conference, Busan, S. Korea, May 13 -16. 